Title:

In a study with adolescents with intellectual disability, drop-out during the study is associated with higher participant burden, while drop-out at study exit is associated with characteristics of the carer and household but not the adolescent.

Full name, highest academic degree, and institutional affiliation and address for each author:

Robert S Ware ${ }^{\mathrm{a}} \mathrm{PhD}$

Lyn McPherson $^{\mathrm{b}}$ MPH

Nicholas G. Lennox ${ }^{\mathrm{b}} \mathrm{PhD}$

a. Menzies Health Institute Queensland, Griffith University, 170 Kessels Road, Nathan QLD 4111, Australia

b. Queensland Centre for Intellectual and Developmental Disability, MRI-UQ, The University of Queensland, Mater Hospital, Raymond Terrace, South Brisbane QLD 4101, Australia

Corresponding Author Name: Robert S. Ware

Corresponding Author Postal Address: Menzies Health Institute Queensland, Griffith University, 170 Kessels Road, Nathan QLD 4111, Australia

Corresponding Author Email Address: R.Ware@griffith.edu.au

Corresponding Author Telephone Number: +61 737359263

\title{
Financial Support
}

The Ask Study was funded by the Australian National Health and Medical Research Council (Grant numbers 401647). This post-trial analysis was not funded. The Australian National Health and Medical Research Council had no role in study design; in the collection, analysis 
and interpretation of data; in the writing of the report; or the decision to submit the article for publication.

\section{Conflict of interest}

Uniquest, a corporate arm of the University of Queensland licenses the Comprehensive Health Assessment Program (CHAP). The trial that this data originated from tested a health intervention consisting of classroom-based education, a health diary, and a health check. The CHAP was the health check investigated in the wider RCT. The royalties from the CHAP license are shared equally between the University of Queensland, the Queensland Centre for Intellectual and Developmental Disability, and the third author (Nicholas G. Lennox). The first author (Robert S. Ware) and second author (Lyn McPherson) have no competing interests.

\section{Submission Declaration}

The submitted work has not been published previously in any form, it is not under consideration for publication elsewhere, its publication has been approved by all authors, and, if accepted, it will not be published elsewhere in the same form, in English or in any other language, including electronically without the written consent of the copyright-holder.

\section{Authorship}

All authors have made substantial contributions to all of the following: (1) the conception and design of the study, or acquisition of data, or analysis and interpretation of data, (2) drafting the article or revising it critically for important intellectual content, (3) final approval of the submitted version.

Word Count of Abstract: 200

Word Count of Manuscript: 2091

Number of References: 21

Number of Tables: 2

Number of Supplementary Tables: 2 


\begin{abstract}
Objective: People with intellectual disability are difficult to retain in longitudinal studies. Research on determinants of study retention for individual-carer dyads, and their reasons for drop-out, are limited. The aim of this study was to investigate characteristics associated with drop-out, and to investigate whether characteristics varied by stage of drop-out.
\end{abstract}

Study Design and Setting: Data are from an Australian randomized trial with adolescents with intellectual disability living in the community. Characteristics of both the adolescent and their nominated carer were collected at baseline. Carers were sent an exit questionnaire approximately two years after enrolment.

Results: Baseline information was available for 566 adolescents: 72(13.0\%) withdrew during the study, and 96(17.3\%) didn't return exit questionnaires. Characteristics associated with drop-out during the study were being in the intervention group, the carer being younger, and the carer not being one of the adolescent's parents. Characteristics associated with withdrawal at exit were carer having lower education and carer having lower socioeconomic status. No adolescent characteristic was associated with drop-out.

Conclusion: Characteristics of drop-outs weren't related to the adolescent and differed according to timing. Drop-out during the study was associated with study burden, whereas characteristics of dropouts at exit interview were associated with lower social position.

Keywords: intellectual disability; epidemiologic methods; health surveys; questionnaires; nonresponse; data collection. 


\section{What is new?}

- In a two-year longitudinal study of adolescents with intellectual disability, drop-out was related to carer, household, and study characteristics but not adolescent characteristics

- Drop-out during the study was associated with higher study burden

- Drop-out at study exit was associated with lower social position

- When designing interventions studies, researchers should focus on designing interventions with similar participant burden in all comparison groups to avoid differential drop-out 


\section{Introduction}

People with intellectual disability have poorer health and shorter lifespans than the general population, as well as high levels of unrecognized disease and inadequate health screening and promotion [1-3]. Despite this health disparity few large epidemiological studies concerning the health of people with intellectual disability have been conducted $[4,5]$. Recruitment and retention in this population is logistically difficult and resource intensive compared to their peers in the general population [6,7]. Extra difficulties include the need for proxy consent when the individual does not have the capacity to provide informed consent [8], the number of gatekeepers that may need to be approached including clinicians, support workers and family members and carers [7], and, should the disability have a genetic cause, the increased likelihood that the family member providing consent may have limited literacy skills. The extensive recruitment efforts required can be expensive making it more financially important to retain participants than in studies of non-disabled populations.

The topic of participant retention in longitudinal studies has received a significant amount of attention in the past decade. For example in the general population, participant retention is associated with female gender [9-11], higher education [11,12], older age [9,12], being married [13], and belief in the importance of the studied topic [14], while strategies that successfully increase retention rates include extra participant contact, offering participants unconditional incentives, and pre-notification phone calls [15]. However there is little published information available on study retention in people with intellectual disability [16]. In particular it is not known whether the characteristics of the person, or their carer, or both, are most likely to influence the likelihood of successfully completing the study. In order to retain participants and their carers in research studies, and hence maintain a study's internal validity, it is important to know what factors are likely to be associated with retention, so that some categories of participants can be specifically targeted for cohort maintenance.

An Australian academic research center has run a large randomized trial investigating a health intervention package in adolescents with intellectual disability living in the community. At study entry the adolescent's nominated carer completed a questionnaire survey. The same carer was invited to complete a follow-up questionnaire at study completion approximately two years later. The aim of this study was to assess the association between adolescent and carer characteristics and participation at follow-up. 


\section{Methods}

The Ask Study is a parallel-group cluster randomized controlled trial undertaken among adolescents with intellectual disability attending secondary school and living in the community in Southern Queensland, Australia, between February 2007 and September 2010 (ClinicalTrials.gov identifier: NCT00519311) [17]. Adolescents eligible to participate in the Ask study were identified through their enrolment at a Special Education School (SES) or Special Education Unit (SEU). SESs are segregated and are attended by children with more significant care needs, while SEUs are located on the campus of a mainstream school. Participants had been assessed by Education Queensland to have an intellectual disability, and were aged 10-18 years on 1 January, 2006. The intervention assessed was a health intervention package, comprising classroom-based health education, a health check, and a health diary for use by the adolescent, their parents/carers and GPs, compared with usual education and medical care. Units of randomization were schools. Ethics approval was granted by both the University of Queensland Behavioral and Social Sciences Ethical Review Committee (\#2004000081) and the Queensland Government Department of Education and the Arts (\#550/27/424). Individual consent to participate was gained from the adolescent's carer.

Baseline questionnaires were sent to the adolescent's carer upon study enrolment. Exit questionnaires were sent approximately two years after baseline to the last known address of carers who had not withdrawn during the course of the study. Schools were contacted for updated contact details when necessary. Participants were categorized according to their stage of drop-out as either returned exit questionnaire, failed to return exit questionnaire, or withdrew before exit questionnaire was distributed.

Telephone interviews were offered at baseline to allow for parents with low literacy for whom responding to a paper-based questionnaire might be problematic. Questionnaires were posted to the participant's residential address. Four weeks after the initial mail-out study staff began making follow-up phone calls to prompt potential participants to return their questionnaires. All carers who had not responded received at least two reminder calls. When carers were contacted by phone the option of a telephone interview was offered (either immediately or at a time of the carer's choosing). Carers were not systematically targeted for telephone interview. Baseline return status was categorized as either postal returner (returned 
questionnaire without phone call), postal returner after phone prompt or telephone responder (completed questionnaire by telephone).

The baseline and exit questionnaires were the same for both intervention and usual care groups, with the addition of questions regarding the usability and benefits of the health intervention package for the intervention group in the exit. Baseline questionnaires asked the age and sex of the adolescent, the etiology of their intellectual disability, and their abilities, and for an assessment of their health. Information on the adolescent's carer and household characteristics, including the adolescents living situation (living with two parents/living with one parent/living with adults other than parents), and the carers reasons for participating in the study were collected. The adolescent's behavioral problems were assessed using the Short Form of the Developmental Behavior Checklist, with adolescents categorized as having no, minor or major problems using pre-defined cut-points of 0.48 and $0.83[18,19]$. Social position was measured at the postcode level using the Australian Bureau for Statistics SocioEconomic Index For Areas of Relative Disadvantage [20]. Trial characteristics recorded were whether the adolescent was allocated to the intervention (yes/no), carer's reason for participating, and baseline return status.

Summary statistics are presented as frequency (percentage). Associations between adolescent/carer characteristics and phase of drop-out were investigated using logistic regression analysis. First univariable analyses were conducted, and then multivariable analyses with adjustment for variables that were univariably significant by the likelihood ratio test. Effect estimates are summarized as odds ratios (OR) and 95\% confidence intervals (95\%CI). Statistical analyses were undertaken using Stata statistical software v14.0 (StataCorp, College Station, TX, USA).

\section{Results}

Of the 592 carers who completed the baseline questionnaire, consent to access medical records could not be obtained from the adolescent's family physician for 26 corresponding adolescents (4.4\%) and they were excluded from the study. Of the remaining 566 participants, 72 (13.0\%) withdrew before exit questionnaires were distributed, 96 (17.3\%) were sent exit questionnaires but did not return them, and 388 (69.8\%) returned exit questionnaires. 
Demographic and clinical characteristics of the adolescents with intellectual disability are summarized in Supplementary Table 1. There were no characteristics of the adolescent multivariably associated with drop-out. Carer, household, and trial characteristics are displayed in Supplementary Table 2. Characteristics identified as being significantly associated with drop-out (at any stage) were carer age and education, social position, living situation, and intervention status. All multivariable models were adjusted for these characteristics. Carer characteristics associated with higher drop-out, after adjusting for potentially confounding variables, included being aged 20-39 years compared with age 40-49 years $(\mathrm{OR}=2.1 ; 95 \% \mathrm{CI}=1.1-4.1)$, and not completing high school $(\mathrm{OR}=2.0 ; 95 \% \mathrm{CI}=1.3-3.0)$. Household characteristics associated with higher drop-out were being located in an area ranked in the lowest fifth for social position, rather than the middle fifth $(\mathrm{OR}=2.2 ; 95 \% \mathrm{CI}=1.2-4.1)$, and the adolescent residing with a non-parent carer compared with living in a two-parent household $(\mathrm{OR}=2.8 ; 95 \% \mathrm{CI}=1.2-6.6)$. Somewhat surprisingly, carers of adolescents allocated to the intervention were more likely not to complete the exit questionnaire $(\mathrm{OR}=1.8 ; 95 \% \mathrm{CI}=1.2-2.7)$. Other trial characteristics, including the carer's motivation for participating in the study, did not affect likelihood of successful follow-up.

When the association between characteristics and the stage of drop-out was considered, there remained no association between adolescent characteristics and study drop-out (Table 1). When carer, household, and trial characteristics were considered (Table 2), the strongest indicator of being likely to withdraw during the study before exit questionnaires were sent was being allocated to the intervention group (OR=4.9;95\%CI=2.4-9.9). Other significantly associated characteristics were being aged 20-39 rather than 40-59 (OR=2.5;95\%CI=1.0-6.6), and residing with a non-parent carer compared with living in a two-parent household $(\mathrm{OR}=3.2 ; 95 \% \mathrm{CI}=1.1-9.0)$. When considering characteristics of carers who did not return exit questionnaires, residing in an area ranked in the lowest fifth for social position, rather than the middle fifth $(\mathrm{OR}=2.8 ; 95 \% \mathrm{CI}=1.8-8.1)$, and the carer not finishing high school $(\mathrm{OR}=2.5 ; 95 \% \mathrm{CI}=1.4-5.0)$ were the only characteristics significantly associated with dropout. 
Table 1: Adolescent characteristics at baseline according to stage of drop-out ( $\mathrm{N}=388$ returned questionnaire; $\mathrm{N}=72$ withdrew before exit interview, $\mathrm{N}=96$ did not return exit interview)

\begin{tabular}{|c|c|c|c|c|c|c|c|c|}
\hline & $\mathbf{N}$ & $\begin{array}{l}\text { Returned exit } \\
\text { questionnaire }\end{array}$ & $\begin{array}{c}\text { Withdrew } \\
\text { during study }\end{array}$ & $\begin{array}{c}\text { Unadjusted OR } \\
(95 \% \mathrm{CI})\end{array}$ & $\begin{array}{c}\text { Adjusted OR } \\
(95 \% \mathrm{CI})\end{array}$ & $\begin{array}{c}\text { Did not return exit } \\
\text { questionnaire }\end{array}$ & $\begin{array}{c}\text { Unadjusted } \\
\text { OR (95\%CI) } \\
\end{array}$ & $\begin{array}{c}\text { Adjusted OR } \\
(95 \% \mathrm{CI})\end{array}$ \\
\hline Total participants & 556 & $388(69.8 \%)$ & $72(13.0 \%)$ & & & $96(17.3 \%)$ & & \\
\hline \multicolumn{9}{|l|}{ Age (years) } \\
\hline$<=14$ & 210 & 146 (69.5\%) & 31 (14.8\%) & 1.0 & 1.0 & $33(15.7 \%)$ & 1.0 & 1.0 \\
\hline $15-16$ & 230 & 162 (70.4\%) & $26(11.3 \%)$ & $0.8(0.4,1.3)$ & $0.9(0.5,1.7)$ & $42(18.3 \%)$ & $1.1(0.7,1.9)$ & $1.2(0.7,2.0)$ \\
\hline$>=17$ & 116 & $80(69.0 \%)$ & 15 (12.9\%) & $0.9(0.5,1.7)$ & $1.2(0.6,2.4)$ & $21(18.1 \%)$ & $1.2(0.6,2.1)$ & $1.3(0.7,2.4)$ \\
\hline \multicolumn{9}{|l|}{ Sex } \\
\hline Male & 295 & 206 (69.8\%) & 38 (12.9\%) & 1.0 & 1.0 & $51(17.3 \%)$ & 1.0 & 1.0 \\
\hline Female & 261 & 182 (69.7\%) & $34(13.0 \%)$ & $1.0(0.6,1.6)$ & $1.1(0.6,1.8)$ & $45(17.2 \%)$ & $1.0(0.6,1.6)$ & $0.9(0.6,1.5)$ \\
\hline \multicolumn{9}{|l|}{ Cause of disability } \\
\hline Down Syndrome & 73 & 59 (80.8\%) & $5(6.9 \%)$ & $0.4(0.1,1.0)$ & $0.5(0.2,1.3)$ & 9 (12.3\%) & $0.6(0.3,1.4)$ & $0.8(0.3,1.6)$ \\
\hline Other syndrome & 312 & $212(68.0 \%)$ & 49 (15.7\%) & 1.0 & 1.0 & $51(16.4 \%)$ & 1.0 & 1.0 \\
\hline Unknown & 171 & 117 (68.4\%) & $18(10.5 \%)$ & $0.7(0.4,1.2)$ & $0.7(0.4,1.4)$ & $36(21.1 \%)$ & $1.3(0.8,2.1)$ & $1.3(0.8,2.1)$ \\
\hline \multicolumn{9}{|l|}{ School type } \\
\hline Special Education Unit & 292 & 211 (72.3\%) & $37(12.7 \%)$ & 1.0 & 1.0 & $44(15.1 \%)$ & 1.0 & 1.0 \\
\hline Special Education School & 264 & 177 (67.1\%) & $35(13.3 \%)$ & $1.1(0.7,1.9)$ & $1.0(0.6,1.8)$ & $52(19.7 \%)$ & $1.4(0.9,2.2)$ & $1.3(0.8,2.0)$ \\
\hline \multicolumn{9}{|l|}{ General Health } \\
\hline Excellent & 158 & $110(69.6 \%)$ & $22(13.9 \%)$ & 1.0 & 1.0 & $26(16.5 \%)$ & 1.0 & 1.0 \\
\hline Very Good & 178 & $133(74.7 \%)$ & $15(8.4 \%)$ & $0.6(0.3,1.1)$ & $0.6(0.3,1.2)$ & $30(16.9 \%)$ & $0.9(0.5,1.7)$ & $1.0(0.6,1.9)$ \\
\hline Good & 164 & $108(65.9 \%)$ & $28(17.1 \%)$ & $1.3(0.7,2.4)$ & $1.2(0.6,2.4)$ & $28(17.1 \%)$ & $1.1(0.6,2.0)$ & $1.2(0.6,2.2)$ \\
\hline Fair/Poor & 56 & 37 (66.1\%) & $7(12.5 \%)$ & $0.9(0.4,2.4)$ & $0.9(0.3,2.5)$ & $12(21.4 \%)$ & $1.4(0.6,3.0)$ & $1.5(0.7,3.3)$ \\
\hline \multicolumn{9}{|l|}{ Physical Mobility } \\
\hline Completely Independent & 481 & $333(69.2 \%)$ & $64(13.3 \%)$ & 1.0 & 1.0 & $84(17.5 \%)$ & 1.0 & 1.0 \\
\hline Independent with help & 38 & $30(79.0 \%)$ & $3(7.9 \%)$ & $0.5(0.2,1.8)$ & $0.6(0.2,2.3)$ & $5(13.2 \%)$ & $0.7(0.2,1.8)$ & $0.7(0.3,1.9)$ \\
\hline Uses wheelchair/immobile & 37 & $25(67.6 \%)$ & $5(13.5 \%)$ & $1.0(0.4,2.8)$ & $0.8(0.3,2.2)$ & $7(18.9 \%)$ & $1.1(0.5,2.7)$ & $1.1(0.5,2.8)$ \\
\hline \multicolumn{9}{|l|}{ Communication } \\
\hline Mainly/Entirely verbal & 424 & $287(67.7 \%)$ & $60(14.2 \%)$ & 1.0 & 1.0 & $77(18.2 \%)$ & 1.0 & 1.0 \\
\hline Verbal with nonverbal aids & 75 & $56(74.7 \%)$ & $8(10.7 \%)$ & $0.7(0.3,1.5)$ & $0.6(0.3,1.5)$ & $11(14.7 \%)$ & $0.7(0.4,1.5)$ & $0.7(0.4,1.5)$ \\
\hline Mainly nonverbal/facilitated & 57 & $45(79.0 \%)$ & $4(7.0 \%)$ & $0.4(0.1,1.2)$ & $0.4(0.1,1.2)$ & $8(14.0 \%)$ & $0.7(0.3,1.5)$ & $0.7(0.3,1.6)$ \\
\hline \multicolumn{9}{|l|}{ Behavior Problems } \\
\hline No & 176 & $123(69.9 \%)$ & $18(10.2 \%)$ & 1.0 & 1.0 & 35 (19.9\%) & 1.0 & 1.0 \\
\hline Minor & 186 & $126(67.7 \%)$ & $27(14.5 \%)$ & $1.5(0.8,2.8)$ & $1.5(0.8,3.0)$ & $33(17.7 \%)$ & $0.9(0.5,1.6)$ & $0.9(0.5,1.5)$ \\
\hline Major & 189 & $136(72.0 \%)$ & 27 (14.3\%) & $1.4(0.7,2.6)$ & $1.4(0.7,2.7)$ & $26(13.8 \%)$ & $0.7(0.4,1.2)$ & $0.6(0.3,1.1)$ \\
\hline
\end{tabular}


Table 2: Carer, household and trial characteristics at baseline according to stage of drop-out ( $\mathrm{N}=388$ returned questionnaire; $\mathrm{N}=72$ withdrew before exit interview, $\mathrm{N}=96$ did not return exit interview)

\begin{tabular}{|c|c|c|c|c|c|c|c|c|}
\hline Characteristic & $\mathbf{N}$ & $\begin{array}{l}\text { Returned exit } \\
\text { questionnaire }\end{array}$ & $\begin{array}{c}\text { Withdrew } \\
\text { during study }\end{array}$ & $\begin{array}{c}\text { Unadjusted } \\
\text { OR }(95 \% C I)\end{array}$ & $\begin{array}{c}\text { Adjusted } \\
\text { OR }(95 \% \mathrm{CI})\end{array}$ & $\begin{array}{c}\text { Did not return } \\
\text { exit questionnaire }\end{array}$ & $\begin{array}{c}\text { Unadjusted } \\
\text { OR }(95 \% \text { CI })\end{array}$ & $\begin{array}{c}\text { Adjusted OR } \\
(95 \% \mathrm{CI})\end{array}$ \\
\hline \multicolumn{9}{|l|}{ Carer characteristics } \\
\hline \multicolumn{9}{|l|}{ Relationship to adolescent } \\
\hline Parent & 512 & $364(71.1 \%)$ & $63(12.3 \%)$ & 1.0 & 1.0 & 85 (16.6\%) & 1.0 & 1.0 \\
\hline Other & 44 & $24(54.6 \%)$ & $9(20.5 \%)$ & $2.2(1.0,4.9)$ & $1.6(0.4,6.3)$ & $11(25.0 \%)$ & $2.0(0.9,4.2)$ & $2.5(0.9,7.0)$ \\
\hline \multicolumn{9}{|l|}{ Age (years) } \\
\hline $20-39$ & 128 & $70(54.7 \%)$ & 28 (21.9\%) & $3.4(1.9,6.3)$ & $2.5(1.0,6.6)$ & $30(23.4 \%)$ & $1.9(1.1,3.2)$ & $1.9(0.8,4.2)$ \\
\hline $40-49$ & 288 & $214(74.3 \%)$ & $25(8.7 \%)$ & 1.0 & 1.0 & $49(17.0 \%)$ & 1.0 & 1.0 \\
\hline $50+$ & 130 & $98(75.4 \%)$ & $16(12.3 \%)$ & $1.4(0.7,2.7)$ & $2.0(0.6,6.6)$ & $16(12.3 \%)$ & $0.7(0.4,1.3)$ & $0.7(0.3,1.8)$ \\
\hline \multicolumn{9}{|l|}{ Gender } \\
\hline Female & 479 & $332(69.3 \%)$ & $58(12.1 \%)$ & 1.0 & 1.0 & $89(18.6 \%)$ & 1.0 & 1.0 \\
\hline Male & 75 & 55 (73.3\%) & $13(17.3 \%)$ & $1.4(0.7,2.6)$ & $1.5(0.8,3.2)$ & $7(9.3 \%)$ & $2.1(0.9,4.8)$ & $1.9(0.8,4.5)$ \\
\hline \multicolumn{9}{|l|}{ Education } \\
\hline Finished high school Yr-12 & 175 & $242(65.6 \%)$ & 19 (10.9\%) & 1.0 & 1.0 & 17 (9.7\%) & 1.0 & 1.0 \\
\hline Did not finish high school Yr-12 & 369 & $139(79.4 \%)$ & $50(13.6 \%)$ & $1.4(0.8,2.5)$ & $1.4(0.8,2.5)$ & 77 (20.9\%) & $2.5(1.4,5.0)$ & $2.5(1.4,5.0)$ \\
\hline \multicolumn{9}{|l|}{ Attended special school } \\
\hline No & 509 & $359(70.5 \%)$ & $65(12.8 \%)$ & 1.0 & 1.0 & $85(16.7 \%)$ & 1.0 & 1.0 \\
\hline Yes & 41 & $24(58.5 \%)$ & $6(14.6 \%)$ & $1.4(0.5,3.5)$ & $1.6(0.6,4.4)$ & $11(26.8 \%)$ & $1.9(0.9,4.1)$ & $1.9(0.9,4.2)$ \\
\hline \multicolumn{9}{|l|}{ English as first language } \\
\hline Yes & 524 & $365(69.7 \%)$ & 67 (12.8\%) & 1.0 & 1.0 & $92(17.6 \%)$ & 1.0 & 1.0 \\
\hline No & 29 & $21(72.4 \%)$ & $4(13.8 \%)$ & $1.0(0.3,3.1)$ & $0.7(0.2,2.3)$ & $4(13.8 \%)$ & $0.8(0.3,2.3)$ & $0.8(0.3,2.4)$ \\
\hline \multicolumn{9}{|l|}{ Household characteristics } \\
\hline Lowest & 63 & $32(50.8 \%)$ & $9(14.3 \%)$ & $1.2(0.5,2.8)$ & $1.0(0.4,2.5)$ & 22 (34.9\%) & $3.5(1.7,7.3)$ & $2.8(1.8,8.1)$ \\
\hline Lower & 127 & $89(70.1 \%)$ & $18(14.2 \%)$ & $0.9(0.4,1.7)$ & $0.8(0.4,1.7)$ & $20(15.8 \%)$ & $1.1(0.6,2.3)$ & $1.2(0.6,2.5)$ \\
\hline Middle & 139 & $97(69.8 \%)$ & $23(16.6 \%)$ & 1.0 & 1.0 & $19(13.7 \%)$ & 1.0 & 1.0 \\
\hline Higher & 123 & $88(71.5 \%)$ & $11(8.9 \%)$ & $0.5(0.2,1.1)$ & $0.7(0.3,1.6)$ & $24(19.5 \%)$ & $1.4(0.7,2.7)$ & $1.6(0.8,3.2)$ \\
\hline Highest & 104 & $82(78.9 \%)$ & $11(10.6 \%)$ & $0.6(0.3,1.2)$ & $0.7(0.3,1.6)$ & $11(10.6 \%)$ & $0.7(0.3,1.5)$ & $0.8(0.4,1.9)$ \\
\hline \multicolumn{9}{|l|}{ Area of residence } \\
\hline Regional & 277 & 192 (69.3\%) & 38 (13.7\%) & 1.0 & 1.0 & $47(17.0 \%)$ & 1.0 & 1.0 \\
\hline Major city & 279 & $196(70.3 \%)$ & $34(12.2 \%)$ & $0.9(0.5,1.5)$ & $0.8(0.5,1.4)$ & $49(17.6 \%)$ & $1.0(0.7,1.6)$ & $1.1(0.7,1.7)$ \\
\hline \multicolumn{9}{|l|}{ Living situation } \\
\hline living with 2 parents & 378 & $271(71.7 \%)$ & 49 (13.0\%) & 1.0 & 1.0 & $58(15.3 \%)$ & 1.0 & 1.0 \\
\hline
\end{tabular}




\begin{tabular}{|c|c|c|c|c|c|c|c|c|}
\hline living with 1 parent & 151 & $103(68.2 \%)$ & $15(9.9 \%)$ & $0.8(0.4,1.5)$ & $0.8(0.4,1.6)$ & $33(21.9 \%)$ & $1.5(0.9,2.4)$ & $1.5(0.9,2.4)$ \\
\hline living with other carers & 25 & $12(48.0 \%)$ & $8(32.0 \%)$ & $3.7(1.4,9.5)$ & $3.2(1.1,9.0)$ & $5(20.0 \%)$ & $1.9(0.7,5.7)$ & $2.5(0.8,7.9)$ \\
\hline \multicolumn{9}{|l|}{ Trial characteristics } \\
\hline No & 234 & $181(77.4 \%)$ & $10(4.3 \%)$ & 1.0 & 1.0 & $43(18.4 \%)$ & 1.0 & 1.0 \\
\hline Yes & 322 & 207 (64.3\%) & $62(19.3 \%)$ & $5.4(2.7,10.9)$ & $4.9(2.4,9.9)$ & $53(16.5 \%)$ & $1.1(0.7,1.7)$ & $1.1(0.7,1.7)$ \\
\hline \multicolumn{9}{|l|}{ Reason for participating } \\
\hline Interventions good idea & 229 & $157(68.6 \%)$ & $29(12.7 \%)$ & 1.0 & 1.0 & $43(18.8 \%)$ & 1.0 & 1.0 \\
\hline Asked by school & 222 & $153(68.9 \%)$ & $29(13.1 \%)$ & $1.0(0.6,1.8)$ & $1.2(0.7,2.2)$ & $40(18.0 \%)$ & $1.0(0.6,1.5)$ & $1.0(0.6,1.7)$ \\
\hline Concern about child's health & 46 & $34(73.9 \%)$ & $7(15.2 \%)$ & $1.1(0.5,2.8)$ & $1.5(0.6,3.9)$ & 5 (10.9\%) & $0.5(0.2,1.5)$ & $0.5(0.2,1.5)$ \\
\hline To help child/others & 29 & $24(82.8 \%)$ & $3(10.3 \%)$ & $0.7(0.2,2.4)$ & $0.9(0.2,3.4)$ & $2(6.9 \%)$ & $0.3(0.1,1.3)$ & $0.3(0.1,1.5)$ \\
\hline \multicolumn{9}{|l|}{ Baseline return status } \\
\hline Postal returner & 262 & 194 (74.1\%) & 31 (11.8\%) & 1.0 & 1.0 & 37 (14.1\%) & 1.0 & 1.0 \\
\hline Postal return after prompt & 159 & $103(64.8 \%)$ & $26(16.4 \%)$ & $1.6(0.9,2.8)$ & $1.5(0.8,2.7)$ & $30(18.9 \%)$ & $1.5(0.9,2.6)$ & $1.6(0.9,2.7)$ \\
\hline Telephone interview & 135 & $91(67.4 \%)$ & $15(11.1 \%)$ & $1.0(0.5,2.0)$ & $1.0(0.5,2.0)$ & $29(21.5 \%)$ & $1.7(1.0,2.9)$ & $1.6(0.9,2.8)$ \\
\hline
\end{tabular}




\section{Discussion}

Adolescent, carer, household, and trial characteristics were examined with regards to their completion of an exit questionnaire more than two years after study entry in a sample of adolescents with intellectual disability living in the community. Successful completion of the follow-up questionnaire was far more influenced by carer, household and trial characteristics than adolescent characteristics; in particular carers who were younger, who had lower social positon and education, and who were not one of the adolescent's parents were less likely to complete the exit questionnaire. Carers of individuals allocated to the intervention group were more likely to drop-out of the study. Likely reasons for drop-out can be observed when considering the stage of drop-out. In particular, characteristics associated with drop-out during the study were younger carer age, the carer not being a parent, and the adolescent being allocated to the intervention group. These withdrawals are likely to be associated with the extra burden on carers in the intervention group during the intervention phase of the study, and the extra contact from study investigators that intervention group carers received when prompted to take their adolescent for a health check, compared to the little or no contact received by the carers of adolescents allocated to the usual care group. Requiring participants to attend their general practitioner for a health check may have been too invasive or difficult for some participants, and led to the extra loss in the health intervention group. Characteristics associated with drop-out during the exit interview phase were lower social position and lower education, both attributes that are conventionally associated with lower likelihood of survey participation in the general population [12].

Results of this study have practical applications for researchers. First, this information may be used to keep adolescents and their carer's with a high risk for dropping out in the study, for example, by considering study designs that impose the minimum amount of burden of carers - or at least designing studies that impose similar burdens on individuals in the intervention and usual care groups to ensure burden-related drop-out is not differentially biased. Second, if researchers choose to adjust for missing data by using imputation or modelling methods, they need to make assumptions about the characteristics of subjects who do not respond. By considering the difference in characteristics by participation status, these results can inform more sophisticated analyses. 
Strengths of this study include the comprehensive attempts made to enroll participants at baseline, ensuring that participants included a wide selection of adolescents with intellectual disability, and that all factors of the disability spectrum were covered. These efforts resulted in a very large sample size for a study in this population. Participants were similar in age and gender to the population of high-school students with intellectual disability from which they were drawn, suggesting the may be generalizable to the wider population of school-attending adolescents with intellectual disability living in the community in both Australia and other developed countries [21]. Other factors may have influenced the drop-out rate in this study which may not necessarily influence the participation rates of other studies involving people with intellectual disability. Cleaver [16] suggested that the ability of an investigator to directly contact a participant, the method of obtaining consent and the invasiveness of the data collection can influence participation. As this sample was recruited through schools, which contributed to an extended consent process, which may have had an adverse effect on participation as we have previously reported [17], the level of contact with participants was reduced, which may have reduced the overall participation rate but there is no reason to believe that this would have biased the results.

In summary, a select group of carers returned exit questionnaires - carers who were younger, of lower social position, and who had greater study burden were less likely to remain in the study. Characteristics of carers who dropped out differed according to the stage of the study, with drop-out according to study burden much higher in intervention than control group participants. These findings should be considered when addressing potential biases introduced by nonresponding participants and when determining which participants should be specifically targeted to curb participant losses in future studies of people with intellectual disability. 


\section{Acknowledgements}

Data collection for this study was supported by a National Health and Medical Research Council of Australia Project Grant, No. 401647.

Further information on the Ask Study, including on all components of the interventions, and data access can be obtained by contacting the authors at qcidd@uq.edu.au. 
Supplementary Table 1: Adolescent characteristics at baseline according to exit interview status $(\mathrm{N}=556)$

\begin{tabular}{|c|c|c|c|c|}
\hline & $\mathbf{N}$ & $\begin{array}{c}\text { Did not } \\
\text { complete exit } \\
\text { interview }\end{array}$ & $\begin{array}{l}\text { Unadjusted } \\
\text { odds ratio } \\
(95 \% \mathrm{CI})\end{array}$ & $\begin{array}{c}\text { Adjusted odds ratio } \\
\text { (95\% CI) }\end{array}$ \\
\hline Total number of participants & 556 & $168(30.2 \%)$ & & \\
\hline \multicolumn{5}{|l|}{ Age (years) } \\
\hline$<=14$ & 210 & $64(30.5 \%)$ & 1.0 & 1.0 \\
\hline $15-16$ & 230 & $68(29.6 \%)$ & $1.0(0.6,1.4)$ & $1.1(0.7,1.7)$ \\
\hline$>=17$ & 116 & $36(31.0 \%)$ & $1.0(0.6,1.7)$ & $1.2(0.7,2.0)$ \\
\hline \multicolumn{5}{|l|}{ Sex } \\
\hline Male & 295 & 89 (30.2\%) & 1.0 & 1.0 \\
\hline Female & 261 & $79(30.3 \%)$ & $1.0(0.7,1.4)$ & $1.0(0.7,1.4)$ \\
\hline \multicolumn{5}{|l|}{ Cause of disability } \\
\hline Down Syndrome & 73 & $14(19.2 \%)$ & $0.5(0.3,0.9)$ & $0.6(0.3,1.2)$ \\
\hline Other syndrome & 312 & $120(36.1 \%)$ & 1.0 & 1.0 \\
\hline Unknown & 171 & $54(31.6 \%)$ & $1.0(0.7,1.5)$ & $1.0(0.7,1.5)$ \\
\hline \multicolumn{5}{|l|}{ School type } \\
\hline Special Education Unit & 292 & $81(27.7 \%)$ & 1.0 & 1.0 \\
\hline Special Education School & 264 & $87(33.0 \%)$ & $1.3(0.9,1.8)$ & $1.2(0.8,1.7)$ \\
\hline \multicolumn{5}{|l|}{ General Health } \\
\hline Excellent & 158 & 48 (30.4\%) & 1.0 & 1.0 \\
\hline Very Good & 178 & $45(25.3 \%)$ & $0.8(0.5,1.3)$ & $0.8(0.5,1.3)$ \\
\hline Good & 164 & $56(34.2 \%)$ & $1.2(0.7,1.9)$ & $1.2(0.7,1.9)$ \\
\hline Fair/Poor & 56 & 19 (33.9\%) & $1.2(0.6,2.3)$ & $1.1(0.6,2.3)$ \\
\hline \multicolumn{5}{|l|}{ Physical Mobility } \\
\hline Completely Independent & 481 & 148 (30.8 \%) & 1.0 & 1.0 \\
\hline Independent with help & 38 & $8(21.1 \%)$ & $0.6(0.3,1.3)$ & $0.7(0.3,1.5)$ \\
\hline Uses wheelchair/immobile & 37 & $12(32.4 \%)$ & $1.1(0.5,2.2)$ & $0.9(0.4,2.0)$ \\
\hline \multicolumn{5}{|l|}{ Communication } \\
\hline Mainly/Entirely verbal & 424 & 137 (32.1\%) & 1.0 & 1.0 \\
\hline Verbal with nonverbal aids & 75 & $19(25.3 \%)$ & $0.7(0.4,1.2)$ & $0.7(0.4,1.3)$ \\
\hline Mainly nonverbal/facilitated & 57 & $12(21.1 \%)$ & $0.6(0.3,1.1)$ & $0.6(0.31 .1)$ \\
\hline \multicolumn{5}{|l|}{ Behavior Problems } \\
\hline No & 176 & $53(30.1 \%)$ & 1.0 & 1.0 \\
\hline Minor & 186 & $60(32.3 \%)$ & $1.1(0.7,1.7)$ & $1.0(0.6,1.6)$ \\
\hline Major & 189 & $53(28.0 \%)$ & $0.9(0.6,1.4)$ & $0.8(0.5,1.3)$ \\
\hline
\end{tabular}


Supplementary Table 2: Carer, household and trial characteristics at baseline according to exit interview status $(\mathrm{N}=556)$

\begin{tabular}{|c|c|c|c|c|}
\hline & $\mathbf{N}$ & $\begin{array}{l}\text { Did not complete } \\
\text { exit interview }\end{array}$ & $\begin{array}{c}\text { Unadjusted } \\
\text { odds ratio } \\
(95 \% \mathrm{CI})\end{array}$ & $\begin{array}{l}\text { Adjusted odds } \\
\text { ratio (95\% CI) }\end{array}$ \\
\hline \multicolumn{5}{|l|}{ Carer characteristics } \\
\hline \multicolumn{5}{|l|}{ Relationship to adolescent } \\
\hline Parent & 512 & $148(28.9 \%)$ & 1.0 & 1.0 \\
\hline Other & 44 & $20(45.5 \%)$ & $2.0(1.1,3.8)$ & $2.1(0.9,4.9)$ \\
\hline \multicolumn{5}{|l|}{ Age (years) } \\
\hline $20-39$ & 128 & $58(45.3 \%)$ & $2.4(1.5,3.7)$ & $2.1(1.1,4.1)$ \\
\hline 40-49 & 288 & $74(25.7 \%)$ & 1.0 & 1.0 \\
\hline $50+$ & 130 & $32(24.6 \%)$ & $0.9(0.6,1.5)$ & $1.1(0.5,2.3)$ \\
\hline \multicolumn{5}{|l|}{ Gender } \\
\hline Male & 75 & $20(26.7 \%)$ & $1.2(0.7,2.1)$ & $1.1(0.6,2.0)$ \\
\hline Female & 479 & $147(30.7 \%)$ & 1.0 & 1.0 \\
\hline \multicolumn{5}{|l|}{ Education } \\
\hline Finished high school year 12 & 175 & $36(20.6 \%)$ & 1.0 & 1.0 \\
\hline Did not finish high school year 12 & 369 & 127 (34.4\%) & $2.0(1.3,3.0)$ & $2.0(1.3,3.0)$ \\
\hline \multicolumn{5}{|l|}{ Attended special school } \\
\hline No & 509 & $150(29.5 \%)$ & 1.0 & 1.0 \\
\hline Yes & 41 & $17(41.5 \%)$ & $1.7(0.9,3.2)$ & $1.8(0.9,3.6)$ \\
\hline \multicolumn{5}{|l|}{ English as first language } \\
\hline Yes & 524 & 159 (30.3\%) & 1.0 & 1.0 \\
\hline No & 29 & $8(27.6 \%)$ & $0.9(0.4,2.0)$ & $1.1(0.4,2.5)$ \\
\hline \multicolumn{5}{|l|}{ Household characteristics } \\
\hline \multicolumn{5}{|l|}{ Social position (fifths) } \\
\hline Lowest & 63 & $31(49.2 \%)$ & $2.2(1.2,4.1)$ & $2.2(1.2,4.1)$ \\
\hline Lower & 127 & 38 (29.9\%) & $1.0(0.6,1.7)$ & $1.0(0.6,1.8)$ \\
\hline Middle & 139 & $42(30.2 \%)$ & 1.0 & 1.0 \\
\hline Higher & 123 & 35 (28.5\%) & $0.9(0.5,1.6)$ & $1.1(0.6,2.0)$ \\
\hline Highest & 104 & $22(21.2 \%)$ & $0.6(0.3,1.1)$ & $0.7(0.4,1.4)$ \\
\hline \multicolumn{5}{|l|}{ Area of residence } \\
\hline Regional & 277 & 85 (30.7\%) & 1.0 & 1.0 \\
\hline Major city & 279 & $83(29.8 \%)$ & $1.0(0.7,1.4)$ & $0.9(0.6,1.3)$ \\
\hline \multicolumn{5}{|l|}{ Living situation } \\
\hline living with 2 parents & 378 & 107 (28.3\%) & 1.0 & 1.0 \\
\hline living with 1 parent & 151 & 48 (31.8\%) & $1.2(0.8,1.8)$ & $1.2(0.8,1.8)$ \\
\hline living with other carers & 25 & $13(52.0 \%)$ & $2.7(1.2,6.2)$ & $2.8(1.2,6.6)$ \\
\hline \multicolumn{5}{|l|}{ Trial characteristics } \\
\hline \multicolumn{5}{|l|}{ Allocated to intervention } \\
\hline No & 234 & $53(22.7 \%)$ & 1.0 & 1.0 \\
\hline Yes & 322 & $115(55.7 \%)$ & $1.9(1.3,2.8)$ & $1.8(1.2,2.7)$ \\
\hline \multicolumn{5}{|l|}{ Reason for participating } \\
\hline Think interventions good idea & 229 & $72(31.4 \%)$ & 1.0 & 1.0 \\
\hline Asked by school & 222 & $69(31.1 \%)$ & $1.0(0.7,1.5)$ & $1.1(0.7,1.7)$ \\
\hline Concerns about health of child & 46 & $12(26.1 \%)$ & $0.8(0.4,1.6)$ & $0.9(0.4,1.8)$ \\
\hline To help child/others & 29 & $5(17.2 \%)$ & $0.5(0.2,1.2)$ & $0.5(0.2,1.5)$ \\
\hline \multicolumn{5}{|l|}{ Baseline return status } \\
\hline Postal returner & 262 & $68(26.0 \%)$ & 1.0 & 1.0 \\
\hline Postal return after prompt & 159 & $56(35.2 \%)$ & $1.6(1.0,2.3)$ & $1.5(1.0,2.4)$ \\
\hline Telephone interview & 135 & $44(32.6 \%)$ & $1.4(0.9,2.1)$ & $1.3(0.8,2.2)$ \\
\hline
\end{tabular}




\section{References}

[1] Cooper SA, Morrison J, Melville C, Finlayson J, Allan L, Martin G, et al. Improving the health of people with intellectual disabilities: outcomes of a health screening programme after 1 year. J Intellect Disabil Res 2006;50:667-77.

[2] Emerson E, Baines S, Allerton L, Welch V. Health Inequalities \& People with Learning Disabilities in the UK: 2012. London: Learning Disabilities Observatory. Available at: http://www.improvinghealthandlives.org.uk/securefiles/140325 0012//IHAL\%20201211\%20Health\%20Inequalities r1.pdf. Accessed May 17, 2017.

[3] Heslop P, Blair PS, Fleming P, Hoghton M, Marriott A, Russ L. The Confidential Inquiry into premature deaths of people with intellectual disabilities in the UK: a population-based study. The Lancet 2014;383:889-95.

[4] Brooker K, van Dooren K, Tseng CH, McPherson L, Lennox N, Ware R. Out of sight, out of mind? The inclusion and identification of people with intellectual disability in public health research. Perspect Public Heal 2015;135:204-11.

[5] Feldman M, Bosett J, Collet C, Burnham-Riosa P. Where are persons with intellectual disabilities in medical research? A survey of published clinical trials. J Intellect Disabil Res 2014;58:800-9.

[6] Lennox N, Taylor M, Rey-Conde T, Bain C, Purdie DM, Boyle F. Beating the barriers: recruitment of people with intellectual disability to participate in research. J Intellect Disabil Res 2005;49:296-305.

[7] Lewis K. Participation of people with a learning disability in medical research. Scoping review. London: MenCap. Available at:

https://old.mencap.org.uk/sites/default/files/documents/Participation\%20of\%20people\%20with\%2 0a\%20learning\%20disability\%20in\%20medical\%20 1.pdf. Accessed May 17, 2017.

[8] lacono T, Murray V. Issues of informed consent in conducting medical research involving people with intellectual disability. J Appl Res Intellect Disabil 2003;16:41-51.

[9] Dunn KM, Jordan K, Lacey RJ, Shapley M, Jinks C. Patterns of consent in epidemiologic research: evidence from over 25,000 responders. Am J Epidemiol 2004;159:1087-94.

[10] Eagan TM, Eide GE, Gulsvik A, Bakke PS. Nonresponse in a community cohort study: predictors and consequences for exposure-disease associations. J Clin Epidemiol 2002;55:775-81.

[11] Hille ET, Elbertse L, Gravenhorst JB, Brand R, Verloove-Vanhorick SP. Nonresponse bias in a follow-up study of 19-year-old adolescents born as preterm infants. Pediatrics 2005;116:e662-6.

[12] Burg JA, Allred SL, Sapp JH, 2nd. The potential for bias due to attrition in the National Exposure Registry: an examination of reasons for nonresponse, nonrespondent characteristics, and the response rate. Toxicol Ind Health 1997;13:1-13.

[13] Partin MR, Malone M, Winnett M, Slater J, Bar-Cohen A, Caplan L. The impact of survey nonresponse bias on conclusions drawn from a mammography intervention trial. J Clin Epidemiol 2003;56:867-73.

[14] Ulrich CM, Knafl KA, Ratcliffe SJ, Richmond TS, Grady C, Miller-Davis C, et al. Developing a Model of the Benefits and Burdens of Research Participation in Cancer Clinical Trials. AJOB Prim Res 2012;3:10-23.

[15] Treweek S, Pitkethly M, Cook J, Kjeldstrom M, Taskila T, Johansen M, et al. Strategies to improve recruitment to randomised controlled trials. Cochrane Db Syst Rev 2010;Issue 4. Art. No.: MR0000.

[16] Cleaver S, Ouellette-Kuntz H, Sakar A. Participation in intellectual disability research: a review of 20 years of studies. J Intellect Disabil Res 2010;54:187-93.

[17] Lennox N, Ware R, Carrington S, O'Callaghan M, Williams G, McPherson L, et al. Ask: a health advocacy program for adolescents with an intellectual disability: a cluster randomised controlled trial. BMC Public Health 2012;12:750.

[18] Taffe JR, Gray KM, Einfeld SL, Dekker MC, Koot HM, Emerson E, et al. Short form of the developmental behaviour checklist. Am J Ment Retard 2007;112:31-9.

[19] Theodoratos O, McPherson L, Franklin C, Tonge B, Einfeld S, Lennox N, et al. Psychopathology of adolescents with an intellectual disability who present to general hospital services. Australas Psychiatry 2017; http://doi.org/10.1177/1039856217706820. 
[20] Australian Bureau of Statistics. The Index of Relative Socio-Economic Disadvantage (IRSD). Canberra: ABS. Available at: http://www.abs.gov.au/websitedbs/censushome.nsf/home/seifa. Accessed May 17, 2017.

[21] Lennox N, McPherson L, Bain C, O'Callaghan M, Carrington S, Ware RS. A health advocacy intervention for adolescents with intellectual disability: a cluster randomized controlled trial. Dev Med Child Neurol 2016;58:1265-72. 